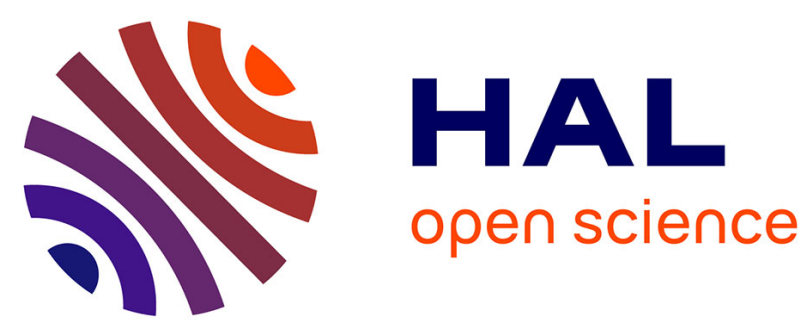

\title{
Using Surface Amide Couplings to Assemble Photocathodes for Solar Fuel Production Applications
}

Kelly Materna, Noémie Lalaoui, Joseph Laureanti, Aaron Walsh, Belinda

Pettersson Rimgard, Reiner Lomoth, Anders Thapper, Sascha Ott, Wendy

Shaw, Haining Tian, et al.

\section{To cite this version:}

Kelly Materna, Noémie Lalaoui, Joseph Laureanti, Aaron Walsh, Belinda Pettersson Rimgard, et al.. Using Surface Amide Couplings to Assemble Photocathodes for Solar Fuel Production Applications. ACS Applied Materials \& Interfaces, 2020, 12 (4), pp.4501-4509. 10.1021/acsami.9b19003 . hal02485807

\section{HAL Id: hal-02485807 https://hal.science/hal-02485807}

Submitted on 25 Nov 2020

HAL is a multi-disciplinary open access archive for the deposit and dissemination of scientific research documents, whether they are published or not. The documents may come from teaching and research institutions in France or abroad, or from public or private research centers.
L'archive ouverte pluridisciplinaire HAL, est destinée au dépôt et à la diffusion de documents scientifiques de niveau recherche, publiés ou non, émanant des établissements d'enseignement et de recherche français ou étrangers, des laboratoires publics ou privés. 


\title{
Using Surface Amide Couplings to Assemble Photocathodes for Solar Fuel Production Applications
}

Kelly L. Materna, ${ }^{a}$ Noémie Lalaoui, ${ }^{a}$ Joseph A. Laureanti, ${ }^{b}$ Aaron P. Walsh, ${ }^{\mathrm{c}}$ Belinda Pettersson Rimgard, ${ }^{a}$ Reiner Lomoth, ${ }^{a}$ Anders Thapper, ${ }^{a}$ Sascha Ott, ${ }^{a}$ Wendy J. Shaw, ${ }^{\mathrm{b}}$ Haining Tian, ${ }^{\mathrm{a}}$ and Leif Hammarström ${ }^{\mathrm{a}^{*}}$

aaDepartment of Chemistry-Ångström Laboratories, Uppsala University, Box 523, SE75120 Uppsala, Sweden.

${ }^{b}$ Pacific Northwest National Laboratory, P.O. Box 999, Richland, Washington 99352, United States

${ }^{\mathrm{c}}$ Ferro Corporation, Penn Yan, NY 14527, United States

*Corresponding author: leif.hammarstrom@kemi.uu.se

\begin{abstract}
A facile surface-amide coupling method was examined to attach dye and catalyst molecules to silatrane-decorated $\mathrm{NiO}$ electrodes. Using this method, electrodes with a push-pull dye were assembled, and characterized by photoelectrochemistry and transient absorption spectroscopy. The dye-sensitized electrodes exhibited hole injection into $\mathrm{NiO}$ and good photoelectrochemical stability in water, highlighting the stability of the silatrane anchoring group and the amide linkage. The amide coupling protocol was further applied to electrodes that contain additional proton reduction nickel catalysts for use in photocathode architectures. Evidence for catalyst reduction was observed during photoelectrochemical measurements and via fs-transient absorption spectroscopy demonstrating the possibility for application in photocathodes.
\end{abstract}

Keywords: solar fuels, photocathode, nickel oxide, silatrane, amide coupling 


\section{Introduction}

Due to the continued large-scale use of fossil fuels, global warming and climate change have become a concern. ${ }^{1}$ To mitigate the worst effects of climate change, alternative energy sources must be employed to generate clean, renewable fuels. Solar energy is a key alternative energy source due to the high solar flux hitting the earth's surface $\left(1.2 \times 10^{5} \mathrm{TW}\right)$, which exceeds the world's current energy demands by $\sim 10,000$ times. $^{2-5}$ To use solar energy to drive renewable fuel synthesis, natural photosynthesis can give inspiration. ${ }^{6}$

To mimic photosynthetic processes, water-splitting dye sensitized photoelectrochemical cells (WS-DSPECs) can be assembled to perform "artificial photosynthesis" by using solar energy to drive renewable fuel synthesis. ${ }^{3,}$ 7-10 WSDSPECs are composed of a photoanode, which performs photocatalytic water oxidation, and a photocathode, which performs photocatalytic fuel-forming reactions, such as proton reduction to form $\mathrm{H}_{2} . \mathrm{H}_{2}$ is an energy dense fuel, having a chemical energy per mass of $142 \mathrm{MJkg}^{-1}$, around three times larger than liquid hydrocarbon fuels. ${ }^{11}$

In WS-DSPECs, the photocathode usually consists of a NiO-based electrode coated with surface-bound dye molecules to absorb the light and perform charge separation, while surface-bound catalyst molecules perform catalysis and generate $\mathrm{H}_{2}$. To operate, the photocathode is illuminated which causes the surface-bound dye molecules to reach their excited state. The excited dye then injects a hole into the $\mathrm{NiO}$ valence band, thereby reducing the dye. The reduced dye can then transfer an electron to a neighboring dye molecule or to a proton reduction catalyst on the $\mathrm{NiO}$ surface. Once the catalyst gains two reducing equivalents, as well as two protons from solution, proton reduction can occur to form $\mathrm{H}_{2}$ gas. ${ }^{12-15} \mathrm{~A}$ major limitation to the overall efficiency of WS-DSPECs is that all of these processes necessary to perform photocatalytic proton reduction must occur before unproductive charge recombination happens. ${ }^{3,8,12,16}$

Significant work has been done to optimize photoanodes in WS-DSPECs (the best of which now reach relatively high photocurrents and efficiencies). ${ }^{3}, 8,9$ Conversely, the photocathode component of WS-DSPECs has not been explored or optimized to the same extent; consequently, the overall performance of tandem WS- 
DSPECs to-date are still poor. ${ }^{7,12,17-19}$ The suboptimal photocathode performance could originate from many factors, including the $\mathrm{NiO}$ electrode, which exhibits slow hole mobility and large losses in efficiency due to charge recombination between holes in the $\mathrm{NiO}$ and reduced dye or catalyst molecules. ${ }^{20-38}$ These issues make developing an efficient photocathode quite difficult. Thus, is it crucial that fundamental studies are performed to gain understanding of the processes occurring in photocathodes if performance is to be rationally improved.

To increase photocathode performance, many photocathode designs have focused on changing the electrode assembly. Methods for assembly include using layer-by-layer strategies, ${ }^{36}, \quad 37, \quad 39-42$ adding hydrophobic layers, ${ }^{43}$ codeposition methods, ${ }^{7}, 23,44-46$ covalently linking the dye and catalyst, ${ }^{47-51}$ using electron shuttling layers, ${ }^{52}$ using supramolecular strategies, ${ }^{53}$ changing the semiconductor material, ${ }^{54}$ and using atomic layer deposition. ${ }^{55}$ While these are all very important studies, the stability of the anchoring group in photocathode architectures has received rather little attention. To the best of our knowledge, only one study has focused on changing the molecules' anchoring group to improve performance. ${ }^{44}$ This is surprising, because it is a common strategy in photoanode assembly methods. ${ }^{3,} 16,56-61$ In photocathodes, stability can be a major issue - if the molecular components do not remain bound on the electrode, then the photocathodes will not function efficiently. ${ }^{12}$, ${ }^{14}$ While carboxylic acids and phosphonic acids are known to have limited stability on metal oxide electrodes under aqueous conditions, they are still the most common anchors used in these systems. ${ }^{12,14,56}$ Conversely, hydroxamic acid and silatrane surface anchors are known to have excellent stability on metal oxide surfaces across a wide $\mathrm{pH}$ range ${ }^{56-60,62-64}$ yet only one study to our knowledge has used hydroxamic acid anchors on NiO-based photocathodes ${ }^{44}$ - and none have used silatranes. ${ }^{44,56-60 \text {, }}$ $62-64$

A silatrane is a pentacoordinate caged silicon atom, such as Sil shown in Figure 1 , and is known to bind to metal oxide surfaces $\left(\mathrm{MOx}: \mathrm{TiO}_{2}, \mathrm{SnO}_{2}, \mathrm{ITO}, \mathrm{Al}_{2} \mathrm{O}_{3}\right)$ via the formation of surface Si-O-M ( $\mathrm{M}$ = metal on surface) bonds with concomitant release of triethanolamine ${ }^{56,63-68}$ To bind silatranes to metal oxide electrodes, the electrodes are typically soaked in a silatrane-containing sensitization solution at $70{ }^{\circ} \mathrm{C}$ for $3-24$ hours. ${ }^{57,58,63,68}$ Recently, a new surface preacidification method has been found to bind the silatrane at room temperature with similar loadings to the $70{ }^{\circ} \mathrm{C}$ sensitization 
process. ${ }^{64}$ Once bound, silatranes remain attached to metal oxide electrodes from $\mathrm{pH}$ 2-11, giving excellent aqueous, electrochemical, and photoelectrochemical stability; thus making them excellent options as anchors also in photocathodes. ${ }^{56,57,63,64,68}$

Since producing photocathodes with high efficiencies is challenging, developing a facile method that would allow for the fast screening of different functional units would be highly desirable. An option is to take advantage of organic chemical reactions and perform them on surfaces, such as the use of surface amide couplings. While amide couplings on surfaces are quite popular in other areas of surface chemistry, ${ }^{69-73}$ thus far, we are not aware of any studies using this method to prepare photocathodes. This method is quite convenient because many dye and catalyst molecules already contain carboxylic acid functional groups, which can be utilized in amide couplings, avoiding tedious organic syntheses of complex dye or catalyst molecules. Instead, surface amide couplings have the potential for facile screening of different electrode assemblies by altering the nature of the carboxylic acid decorated dye or catalyst, the amino-derivatized electrode surface, or vice versa. Screening amide coupled combinations of carboxylic acid functionalized dye or catalysts with amino-functionalized molecules that are commercially available or already present in research groups would be a fast and easy strategy to find optimal photocathode combinations. Thus, here we report a method to assemble photocathodes using surface amide couplings with silatrane-anchored molecules. We then use this method to assemble model photocathodes containing a catalyst molecule, and investigate their photoelectrochemical behavior and charge transfer dynamics, to show the applicability of the method. We expect that the protocols presented here will be of general use in the photocathode field.

\section{Results \& Discussion:}

Recently, we developed a new push-pull dye, PB6 (Figure 1), which has been studied on $\mathrm{NiO}$ electrodes using new core-shell assemblies. ${ }^{52,74,75}$ Upon excitation, PB6* $^{*}(1.03 \mathrm{~V} \text { vs. NHE for PB6*/PB6 })^{74}$ exhibits ultrafast hole injection ( $<200 \mathrm{fs}$ ) into the $\mathrm{NiO}$ valence band $(0.5 \mathrm{~V} \text { vs. } \mathrm{NHE})^{76}$; the resulting generated reduced state $(-0.93$ $\checkmark$ vs. NHE) of PB6 is capable of reducing a wide range of proton reduction catalysts, making it a suitable choice as a photocathode dye molecule. ${ }^{74,75}$ PB6 also exhibits a strong absorption band at $530 \mathrm{~nm}$ making it facile to characterize by UV-Vis 
spectroscopy and so monitor its surface binding to NiO. Thus, we sought out to investigate the surface-amide coupling method using PB6.

To prepare the electrodes, $\mathrm{NiO}$ electrodes were first sensitized with 3aminopropylsilatrane, Sil, (Figure 1) via a newly reported preacidification method ${ }^{64}$ allowing the silatrane to bind to the $\mathrm{NiO}$ at room temperature overnight. Briefly, $\mathrm{NiO}$ electrodes were soaked in $0.1 \mathrm{M}$ phosphate buffer at $\mathrm{pH} 2$ for one hour at room temperature. The pre-acidified electrodes were then air-dried (without rinsing), soaked in an $8 \mathrm{mM}$ Sil solution in acetonitrile overnight at room temperature, and rinsed with acetonitrile three times, affording the NiO-Sil electrodes. With aminoderivatized electrodes in hand, we next performed the surface-amide coupling by soaking NiO-Sil in the presence of $0.2 \mathrm{mM}$ PB6 and $2 \mathrm{mM}$ 1-ethyl-3-(3dimethylaminopropyl) carbodiimide (EDC), used as the amide coupling agent in a 1:1 dichloromethane:methanol solution, affording NiO-Sil-PB6 electrodes (Scheme 1). A $2 \mathrm{mM}$ concentration of EDC concentration provided the highest PB6 loadings by UVVis spectroscopy (Figure S2), and was used for all subsequent electrode sensitizations. It should be noted that the concentration and choice of the amidecoupling agent must be screened to optimize molecule loadings.

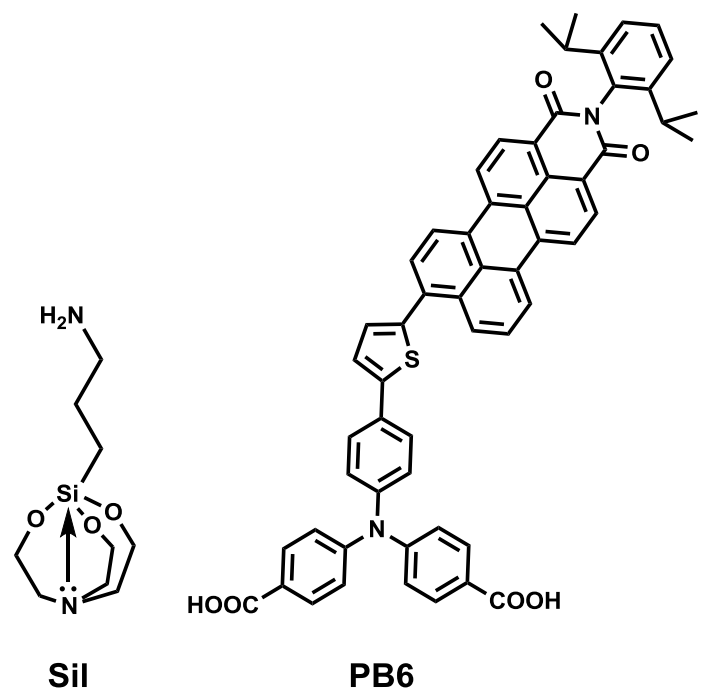

Figure 1. Structures of Sil and PB6 used to assemble the amide coupled electrodes. 


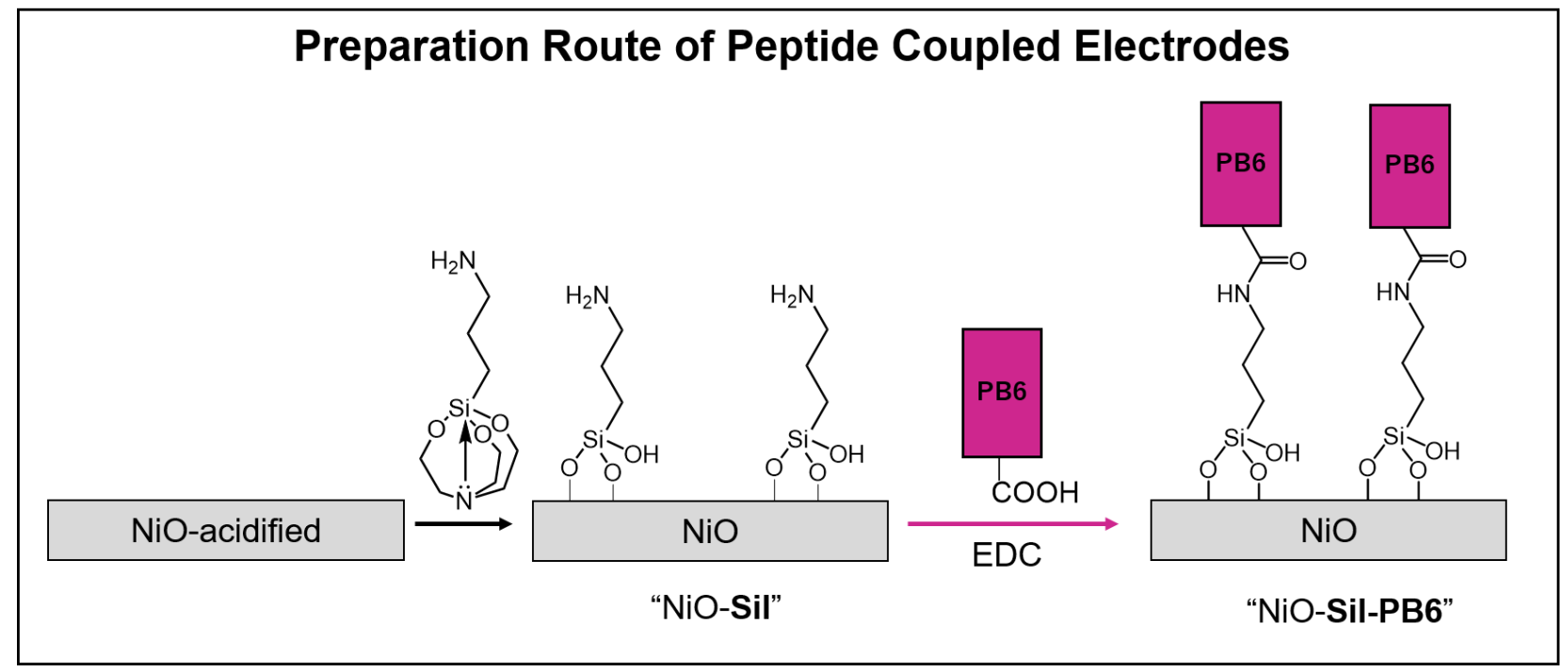

Scheme 1. Amide coupling assembly method of NiO-Sil-PB6 electrodes. Only one of the carboxylic acid groups on PB6 is depicted here for simplicity.

\section{Spectroscopic Characterization.}

The electrodes were characterized by several spectroscopic methods at each stage of the assembly process. Since Sil has only UV absorption features, UVVis spectroscopy could not be used to characterize the electrodes after the first assembly step (NiO-Sil) due to the scattering of the $\mathrm{NiO}$ film below $400 \mathrm{~nm}$ (Figure S6). Instead, evidence for Sil binding to $\mathrm{NiO}$ was obtained by comparing the ATRFTIR spectra of the Sil powder to the NiO-Sil electrodes, which show similar features (Figure S9). Sil exhibits diagnostic signatures of the silatrane cage: a sharp peak at $1175 \mathrm{~cm}^{-1}$ for $\mathrm{v}(\mathrm{C}-\mathrm{O})$ and $1452 \mathrm{~cm}^{-1}$ for $\delta\left(\mathrm{CH}_{2}\right)$, which disappear upon surface binding, indicating silatrane deprotection. Furthermore, a broad peak around 1070 $\mathrm{cm}^{-1}$ appears, suggesting the formation of Si-O-Si cross links and $\mathrm{Si}-\mathrm{O}$ surface bonds (Figure S9). ${ }^{68,77,78}$ ICP-OES measurements also detected $\mathrm{Si}$ on the digested electrode surfaces above background $\mathrm{Si}$ signals, confirming the presence of $\mathrm{Si}$ on the $\mathrm{NiO}$ (Table S2).

Next, we characterized the subsequent amide coupling of PB6 on NiOSil by UV-Vis spectroscopy. When NiO-Sil was exposed to both PB6 and EDC, a strong absorption at $530 \mathrm{~nm}$ appeared, supporting successful attachment of PB6 to the electrode with a surface coverage equivalent to $\sim 40 \mathrm{nmol} \mathrm{cm}^{-2}$ of PB6 (Figure 2). In addition, the absorption features of NiO-Sil-PB6 were similar to separately 
prepared NiO-PB6 electrodes lacking Sil, suggesting the PB6 structure was retained upon binding to NiO-Sil (Figure 2).

To gain further evidence for the amide coupling, several control experiments were performed to test if the observed PB6 was bound via amide bonds or physisorbed to the surface directly. First, we tested for the necessity of the formation of an amide bond. To do this, we made a preacidified $\mathrm{NiO}$ electrode without Sil, soaked the electrode in a solution containing both PB6 and EDC overnight, and monitored the absorption of the electrode by UV-Vis spectroscopy. As expected, no significant binding of PB6 to the electrodes was seen, supporting that physisorption of PB6 does not occur and the amine is essential for binding the dye molecule to the surface (Figure S3). To further confirm amide coupling, we also tested if EDC was needed by exposing NiO-Sil electrodes in a PB6 solution overnight without EDC present. We observed a minute peak in the UV-Vis spectrum at $530 \mathrm{~nm}$ suggesting some PB6 had bound to the surface, likely filling in any open binding sites on the electrode not already taken by Sil (Figure S3). Since we had more significant loading in the presence of EDC, it suggests that an amide coupling is the immobilization mechanism for PB6 loading.

To further confirm that the core PB6 structure was unchanged upon electrode attachment, ATR-FTIR spectroscopic measurements were performed. Comparison of the ATR-FTIR spectra of NiO-Sil-PB6 with PB6 powder samples revealed excellent overlap, further supporting retention of the original PB6 structure on the electrode (Figure 2). When NiO-Sil-PB6 was compared to NiO-PB6, we observed an extra broad peak at $\sim 1070 \mathrm{~cm}^{-1}$, also observed in NiO-Sil electrodes in Figure S9, suggesting the presence of the silatrane on the NiO-Sil-PB6 electrode (Figure 2). This also confirms that the silatrane remains surface-bound during the amide coupling procedure. 

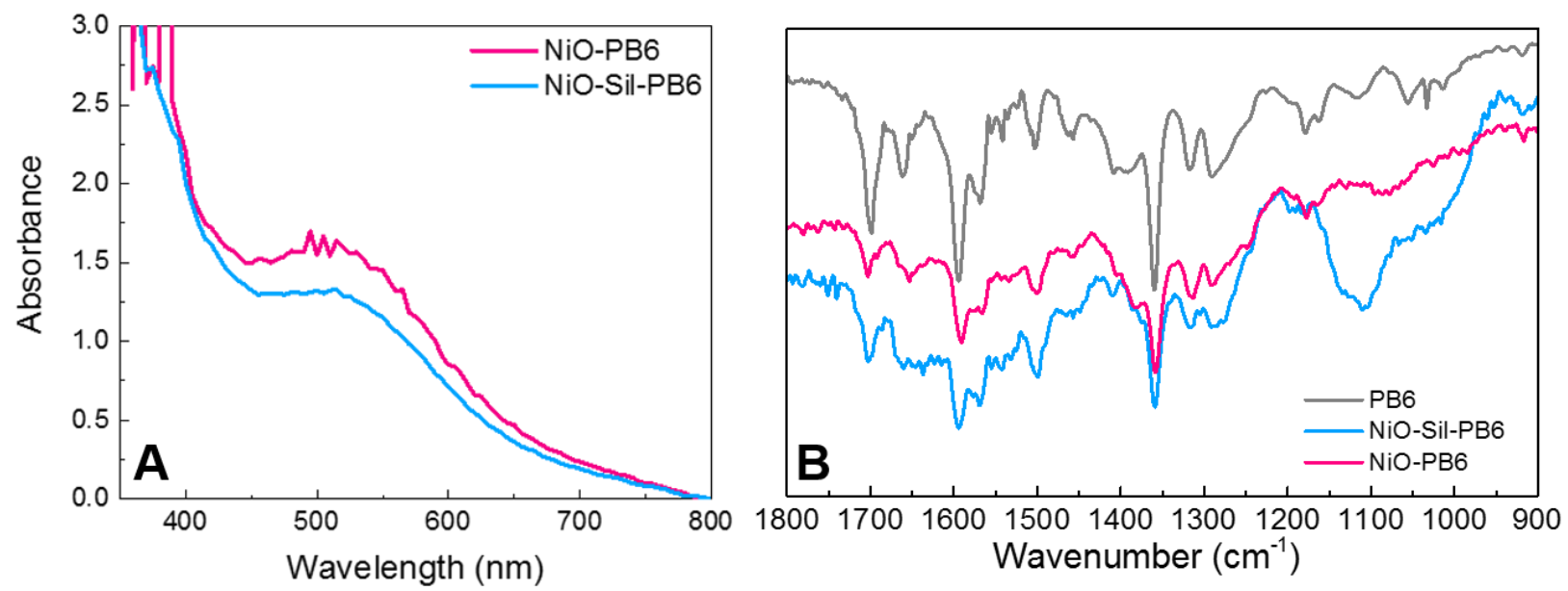

Figure 2. UV-Vis (A) and ATR-FTIR (B) spectra of NiO-Sil-PB6 electrodes (blue) and NiO-PB6 electrodes (pink). PB6 powder ATR-FTIR is shown in grey in panel (B). These data show that PB6 is on the electrode and that it's structure is retained.

\section{Photoelectrochemical Measurements.}

After confirming that electrodes could be prepared using surface amide couplings, photoelectrochemical experiments on the NiO-Sil-PB6 electrodes were performed. Specifically, we probed if the electrodes could generate photocurrent under illumination with an applied bias, which is necessary if they are to be applied into photocathodes. Indeed, an increase in reductive photocurrent in the linear sweep voltammogram (LSV) was observed upon illuminating the NiO-Sil-PB6 electrodes in 0.1 M MES buffer at pH 5, suggesting that PB6 reaches its excited state and injects a hole into the $\mathrm{NiO}$ valence band (Figure 3). One should also keep in mind that photocurrent could also result from the formation of $\mathrm{Ni}(0)$ species via reduction by PB6. $^{79}$ Since the NiO-Sil-PB6 electrodes could produce photocurrent, we then wanted to demonstrate that the PB6 $^{-}$generated after hole injection could transfer an electron to an acceptor molecule. To test this, NiO-Sil-PB6 electrodes were examined in the presence of an irreversible electron acceptor, chloropentaaminecobalt(III) chloride. When LSV was performed in the presence of the acceptor molecule, a significant increase in photocurrent was observed (almost $300 \mu \mathrm{A} \mathrm{cm}^{-2}$ ), strongly suggesting that PB6 $^{-}$is capable of transferring an electron to the acceptor molecule (Figure 3). This finding supports that the NiO-Sil-PB6 
electrodes could be used in combination with surface-bound catalyst molecules for hydrogen production with high photocurrents in optimized solar fuel systems.

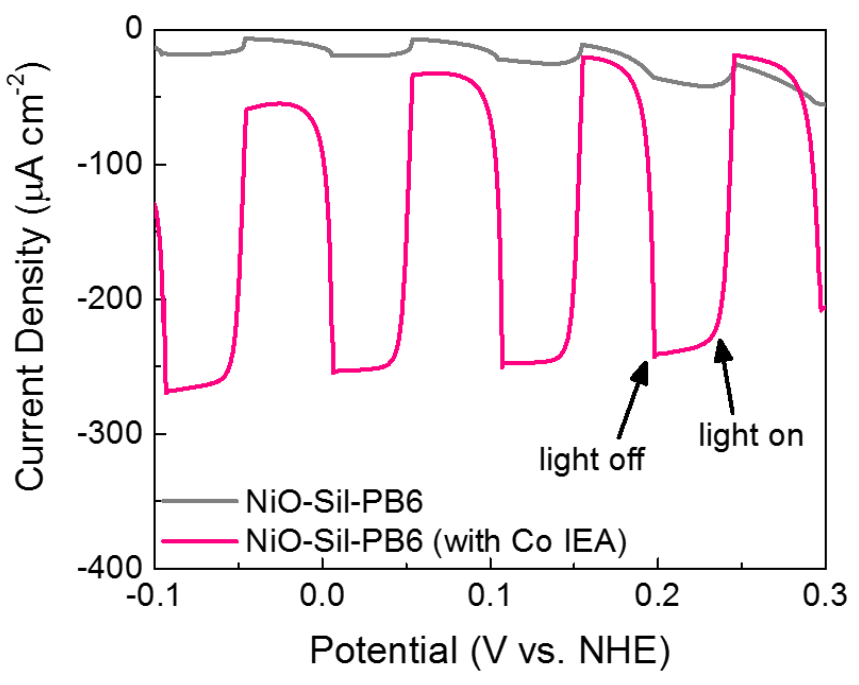

Figure 3. NiO-Sil-PB6 electrodes with (pink) and without (grey) a $10 \mathrm{mM}$ chloropentaaminecobalt chloride electron acceptor (Co IEA) in $0.1 \mathrm{M}$ MES buffer at $\mathrm{pH} 5$ with a scan rate of $5 \mathrm{mV} / \mathrm{s}$. LSV were scanned from positive to negative potentials with the light chopped every $50 \mathrm{mV}$. Samples were illuminated using a white LED with $100 \mathrm{~mW} \mathrm{~cm}^{-2}$.

\section{Ultrafast Electron Transfer Dynamics.}

Since the photoelectrochemical experiments showed promise for the NiO-Sil-PB6 electrodes, we wanted to further understand the charge transfer dynamics on the electrodes. To monitor the electron transfer dynamics, femtosecond transient absorption spectroscopy (fsTAS) was performed on the films in air. NiO-SilPB6 was excited at $560 \mathrm{~nm}$, resulting in a ground state bleach around $530 \mathrm{~nm}$ and an induced absorption at $>620 \mathrm{~nm}$ (Figure 4, S14), both of which had been previously observed with NiO-PB6 electrodes. ${ }^{74}$ Similar to the NiO-PB6 films studied previously, we also observed an isosbestic point at ca. $625 \mathrm{~nm}$ at ca. $0.6 \mathrm{ps}$ after excitation which blueshifts rapidly with time. ${ }^{74} \mathrm{~A}$ global fit to the NiO-Sil-PB6 data to a sum of three exponentials with a minor offset, $\tau_{\text {infinite, }}$ resulted in the following lifetimes: $\tau_{1}=$ $0.53 \mathrm{ps}, \tau_{2}=16 \mathrm{ps}$ and $\tau_{3}=3800 \mathrm{ps}$. A kinetic trace at $620 \mathrm{~nm}$ (Figure 4) shows clearly an instrument-limited bleach, followed by a $\tau_{1}=0.53 \mathrm{ps}$ rise to a positive 
signal and finally a decay to baseline in ca. $1 \mathrm{~ns}$ (represented by $\tau_{2}$ and $\tau_{3}$ ). This shows clearly the presence of at least one intermediate in the photoreaction, consistent with formation of a charge separated state, $\mathrm{PB6}^{-}$and $\mathrm{NiO}^{(+)}$, where the former species has shown an absorption around $620 \mathrm{~nm}^{74} \mathrm{In}$ addition, this is reflected in the decay associated spectra from the global fit, where the $\tau_{1}$ component matches the transient spectrum of excited PB6* while the $\tau_{2}$ and $\tau_{3}$ components are similar to the PB6 $^{-}$radical-ground state difference spectrum (Figure S19-S20). ${ }^{74,75}$ The first component $\left(\tau_{1}\right)$ is attributed to hole injection from excited PB6* to $\mathrm{NiO}$, forming the PB6 $^{-}$radical anion in analogy to previous studies. ${ }^{74}$ Stimulated emission from PB6* $^{*}$ gives a negative signal, that is replaced by the positive absorption of PB6 at $620 \mathrm{~nm}$ (Figure 4). ${ }^{60}$ The slower components $\left(\tau_{2}\right.$ and $\tau_{3}$ ) are attributed to charge recombination between PB6 $^{-}$and $\mathrm{NiO}$ holes, as has been previously observed for NiO-PB6 films. ${ }^{74}$ Note that the kinetics on dye-semiconductor interfaces is in general heterogeneous. Therefore, injection and recombination on $\mathrm{NiO}$ often occurs on overlapping time scales, and the same process may be represented by more than one time constant. ${ }^{20,80}$ Consequently, the time constant values reported here should not be taken as precise measures of the lifetime of a species or process. The PB6 band at $620 \mathrm{~nm}$ is less pronounced in this data than in ref. ${ }^{74}$; we tentatively explain this change by use of a different $\mathrm{NiO}$ preparation here (see experimental section in SI) which leads to more overlap between the slow components of excited state hole transfer and the rapid components of recombination in the present cases. 

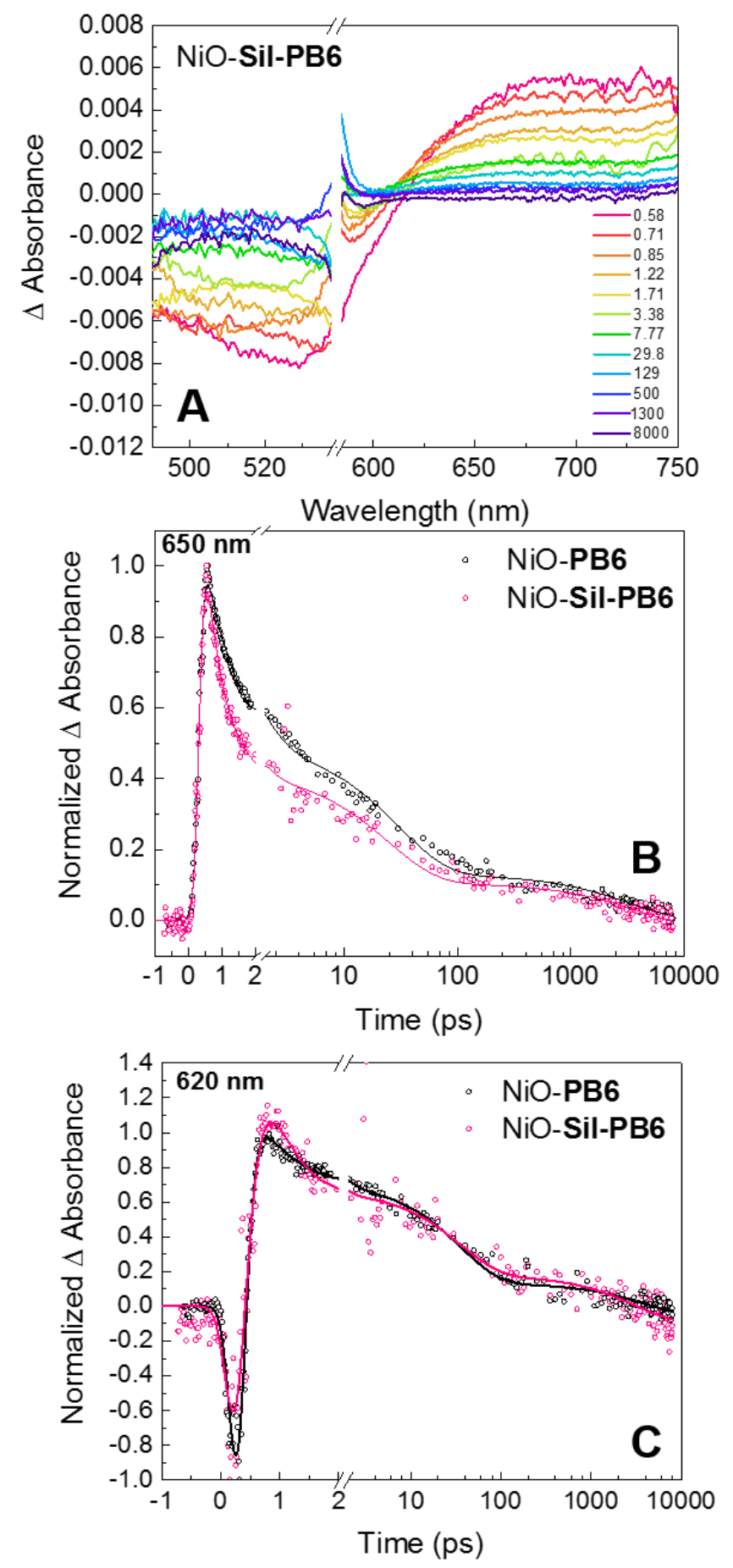

Figure 4. (A) Transient absorption spectra of NiO-Sil-PB6 excited at $560 \mathrm{~nm}$ scattering of the pump light occurs between 550-570 nm. Traces at several time points are depicted in units of ps. (B) kinetic traces at $650 \mathrm{~nm}$ comparing NiO-PB6 (black) and NiO-Sil-PB6 (pink). (C) kinetic traces at $620 \mathrm{~nm}$ comparing NiO-PB6 (black) and NiO-Sil-PB6 (pink).

Since we used a different $\mathrm{NiO}$ preparation than our prior work, we also performed fsTAS on NiO-PB6 electrodes to more reliably compare them to the NiO- 
Sil-PB6 electrodes using the same preparation method for $\mathrm{NiO}$. By direct comparison of the traces at $650 \mathrm{~nm}$ in Figure 4 it is clear that the silatrane anchor in NiO-Sil-PB6 mediates interfacial electron transfer at least as well as the carboxylic anchor in NiOPB6, possibly even giving a somewhat faster hole injection, while the charge recombination rate constant is similar with the two anchors. The trace at $620 \mathrm{~nm}$ displays very similar behavior for the two dyes, showing that the rate and yield of PB6 ${ }^{-}$formation is essentially the same (Figure 4).

Kinetic traces at $650 \mathrm{~nm}$ show ultrafast hole injection for NiO-Sil-PB6 electrodes with the silatrane anchor, which has a similar decay to NiO-PB6 without a silatrane present (Figure 4). Since Sil has a propyl group, theoretically placing PB6 further from the $\mathrm{NiO}$ electrode, a slower hole injection relative to the NiO-PB6 sample would have been expected. The fast decay observed with NiO-Sil-PB6 can be explained by the flexibility of the propyl group of Sil; this flexibility could move PB6 closer to the $\mathrm{NiO}$ surface, thus allowing for ultrafast hole injection into the $\mathrm{NiO}$ and also increase recombination pathways between $\mathrm{PB}^{-}$and $\mathrm{NiO}\left(\mathrm{h}^{+}\right)$.

\section{Electrode Stability.}

To probe the stability of the silatrane-anchored electrodes we monitored the changes on the NiO-Sil-PB6 electrodes before and after photoelectrolysis at 0.1 $\mathrm{V}$ vs. NHE for one hour in $0.1 \mathrm{M}$ MES buffer at $\mathrm{pH} 5$ without the chloropentaaminecobalt chloride electron acceptor. The UV-Vis spectra were unchanged after photoelectrolysis (Figure S8), suggesting that the PB6 structure was retained on the electrode. In addition, no leaching of PB6 into the electrolyte was observed (Figure S8), supporting a stable binding of PB6-Sil to the electrode. ATRFTIR spectra post electrolysis also remained unchanged (Figure S9), showing that the silatrane had remained surface bound and that the PB6 structure had not significantly changed. Furthermore, ICP-OES measurements showed that a majority of the silatrane had been retained on the electrode post photoelectrolysis, further confirming the good stability of this anchoring group on $\mathrm{NiO}$ (Figure S1). In addition, it should be noted that the stability of NiO-Sil-PB6 electrodes was similar to that of the NiO-PB6 electrodes (Figure S8, S9, and S11), which both exhibited excellent stability. There has been some debate regarding the stability of carboxylic acid anchors on $\mathrm{NiO} .^{12}$ The anchor has a less predictable stability than on other metal oxide surfaces $\left(\mathrm{TiO}_{2}, \mathrm{SnO}_{2}, \mathrm{ITO}\right)$, which tend to retain carboxylic acids anchored 
molecules only(?) at $\mathrm{pH}<4$. However, the binding of carboxylic acid anchors on $\mathrm{NiO}$ does not always follow this trend and is sometimes stable at $\mathrm{pH}>4($ ?), which could partially explain the stability of NiO-PB6.

\section{Electrodes with Catalyst}

Since NiO-Sil-PB6 showed promise photoelectrochemically, exhibited electron injection into $\mathrm{NiO}$, and had good stability, we then assembled electrodes by amide coupling a carboxylic acid-derivatized Ni catalyst, NiCyGly (Figure 5), to show the applicability of the new assembly method in photocathodes. NiCyGly has previously been shown to have excellent activity for proton reduction catalysis in water over a wide $\mathrm{pH}$ range, ${ }^{81-85}$ having an onset potential for proton reduction catalysis at -0.808 $\mathrm{V}$ vs. $\mathrm{FeCp}_{2}{ }^{+/ 0}$ at $\mathrm{pH} 5$ under aqueous conditions. ${ }^{82}$

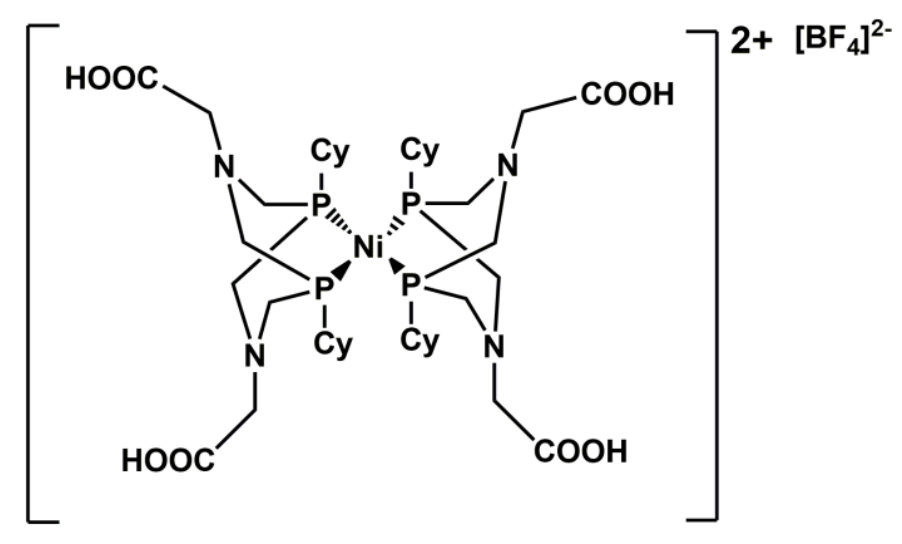

Figure 5. NiCyGly catalyst.

The catalyst-incorporated electrodes were prepared via a co-immobilization method, where NiO-Sil electrodes were soaked in a solution containing both PB6 and NiCyGly in either 2:1 or 1:1 PB6:NiCyGly ratio in the presence of EDC (experimental details in SI). The UV-Vis spectra of the sensitized films show a slight change in surface PB6:NiCyGly ratio as the PB6:NiCyGly ratio is decreased (Figure S7), as seen by the decrease in PB6 absorbance at $530 \mathrm{~nm}$, suggesting the ratios on the surface had been changed. NiCyGly has peaks in the visible region of the spectrum ( 306, $535 \mathrm{~nm})$, but are masked due to the high extinction coefficient of the PB6 dye (Figure S4) and scattering of NiO below $400 \mathrm{~nm}$ (Figure S5). Even the NiOSil-NiCyGly electrodes without PB6 do not show any UV-Vis absorption features from NiCyGly, which was expected due to the thick, highly absorbing $\mathrm{NiO}$ film (Figure S5). However, the decrease in PB6 absorbance in the photocathodes' UV- 
Vis spectra with changing PB6:Ni ratio (Figure S7) indirectly suggests that NiCyGly can bind to the $\mathrm{NiO}$ electrode and occupy surface sites that were once occupied by PB6 in the dye only electrodes, so lowering the overall PB6 absorbance.

To verify that NiCyGly could bind to NiO-Sil, we used the depletion method to screen for NiCyGly-Sil binding. This was done by monitoring a NiCyGly sensitization solution before and after soaking a NiO-Sil electrode overnight in the presence of EDC; a decrease in solution UV-Vis absorption was observed supporting that some of the NiCyGly in solution had bound to the NiO-Sil electrode surface (Figure S5). In addition, the ATR-FTIR spectra of the NiO-Sil-NiCyGly show the presence of the silatrane $\left(\sim 1070 \mathrm{~cm}^{-1}\right)$, indicating that Sil is retained on the surface. Taken together with the depletion method results, this suggests that NiCyGly is likely amide coupled to Sil. Finally, actual surface PB6:NiCyGly ratios were estimated (SI for details) and suggested that samples prepared with a 2:1 sensitization solution resulted in electrodes with a 3:1 surface ratio (labeled as NiO-Sil-PB6-NiCyGly-(3:1)), and those prepared with a 1:1 sensitization solution resulted in a 2:1 surface ratio (labeled as NiO-Sil-PB6-NiCyGly-(2:1)).

Since NiO-Sil-PB6 showed promising photocurrents in the presence of an irreversible electron acceptor, we performed photoelectrochemical measurements on the catalyst-containing photocathodes in $0.1 \mathrm{M}$ MES buffer at $\mathrm{pH} 5$ to test their response to light. With both linear sweep voltammetric (LSV) and chronoamperometric (CA) measurements a higher photocurrent was seen when the catalyst was present on the electrode, suggesting catalyst reduction by PB6-' (Figure 6 , S12). In addition, LSVs were also collected of several control samples (NiO, NiOacidified, NiO-Sil, and NiO-Sil-NiCyGly). None showed a response to light, suggesting that neither the $\mathrm{NiO}$ surface, NiO-acidified surface, Sil, or NiCyGly alone was responsible for the photocurrent in the fully assembled electrodes (Figure S13), but that it was generated through the photoexcitation of PB6. We will focus on the CA results here, as they showed a more reliable steady-state photocurrent than the LSV results (see SI).

Chronoamperometry $(\mathrm{CA})$ was performed on the photocathodes using a $0.1 \mathrm{~V}$ vs. NHE bias while under illumination (Figure 6). All samples with NiCyGly show an increase in photocurrent compared to the NiO-Sil-PB6 sample, suggesting catalyst reduction by PB6 $^{-}$was occurring, while the current from the sample without 
catalyst, NiO-Sil-PB6, is essentially negligible under steady-state conditions. Moreover, higher absolute photocurrent density $(|\mathrm{J}|)$ was observed with the $2: 1$ ratio $\left(|\mathrm{J}|_{20 \min } \sim 12 \mu \mathrm{A} \mathrm{cm}^{-2}\right)$ compared to the $3: 1$ ratio $\left(|\mathrm{J}|_{20 \min } \sim 2 \mu \mathrm{A} \mathrm{cm}{ }^{-2}\right)$ under steadystate conditions suggesting this was the better surface ratio. This trend in photocurrent was reproducible when the CAs were repeated. All samples show a relatively stable photocurrent with only a $20 \%$ decrease in photocurrent over one hour of illumination. Furthermore, we were not able to detect any NiCyGly desorption into the MES buffer after photoelectrolysis, suggesting the catalyst was retained on the electrode surface (Figure S8). In fact, ICP-EOS measurements showed that a majority of the silatrane had been retained on the electrode post photoelectrolysis, highlighting the excellent stability of the anchoring group on $\mathrm{NiO}$ even with a catalyst present (Figure S1).

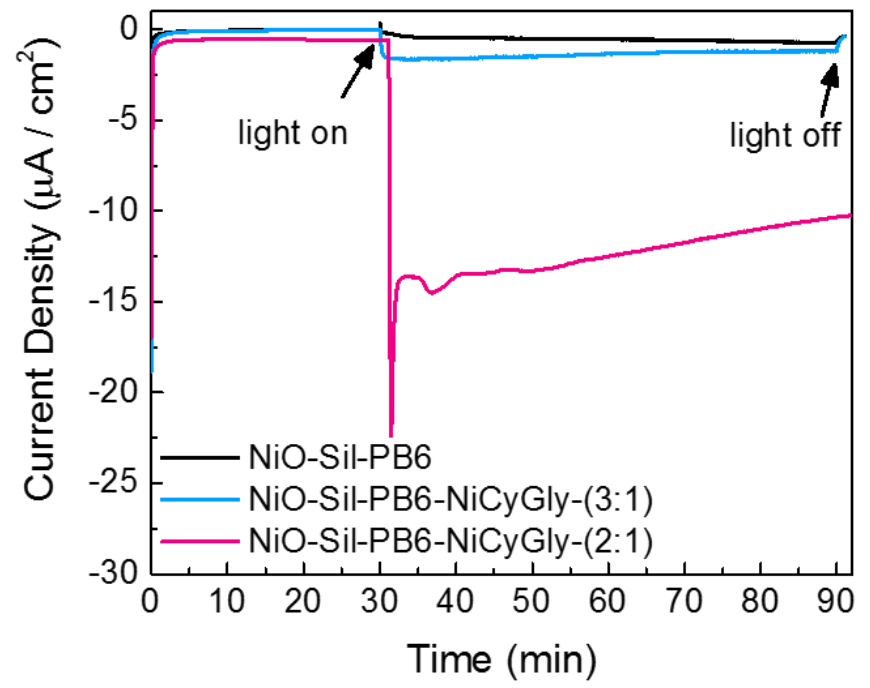

Figure 6. CA of photocathodes containing NiCyGly catalysts: NiO-Sil-PB6-NiCyGly(3:1) (blue), NiO-Sil-PB6-NiCyGly-(2:1) (pink). NiO-Sil-PB6 sample is shown in black for reference. A bias of $0.1 \mathrm{~V}$ vs. NHE was applied during these measurements in 0.1 M MES at pH 5. Samples were illuminated (100 $\mathrm{mW} \mathrm{cm}^{-2}$, white LED) for one hour as indicated by the arrows in chronoamperogram.

Since the photoelectrochemical results suggested possible catalyst reduction by PB6-, we turned to fs-transient absorption spectroscopy to look for further evidence of catalyst reduction. When a catalyst is present on the electrode, we would expect that electron transfer from the reduced dye to a catalyst on the surface would shorten the $\tau_{2}$ and $\tau_{3}$ lifetimes representing disappearance of the 
generated PB6-. Indeed, global analysis results show a decrease in $\tau_{3}$ from 3810 ps for NiO-Sil-PB6 to 1460 ps for NiO-Sil-PB6-NiCyGly-(3:1) and to 2610 ps for NiOSil-PB6-NiCyGly-(2:1) (Table S5). Direct comparison of the lifetimes in multiexponential fits has great uncertainties as different kinetic traces could overlap and effect each other's time constants. However, in this case, the $\tau_{2}$ component is more than 100 times faster than $\tau_{3}$ and $\tau_{\text {infinite }}$ only has a minor amplitude (Figure S19). Therefore, we believe that the difference between the $\tau_{3}$ component in the samples is significant and indicates electron transfer from PB6 $^{-}$to the catalyst. In addition, we would have expected $\tau_{2}$ to be shortened upon addition of catalyst. However, the $\tau_{2}$ components are quite similar between the samples. To explain this similarity, it is important to recall that the PB6 $^{-}$signal observed on our samples is less distinct than our prior work. ${ }^{74}$ Because of this weakened signal, we propose that a large fraction of the excited state decay is included in the $\tau_{2}$ component, which are not affected by the addition of the catalyst, thus explaining the similarity in $\tau_{2}$ between the samples. Furthermore, the traces at $620 \mathrm{~nm}$ show that the maximum signal is much smaller in the presence of catalyst (Figure 7), and the differences in amplitude are much larger than the differences in dye loadings. This would suggest that at least a part of the reduced dye molecules transfers an electron to the catalyst on a time scale of just a few ps. This is similar to what was found in a system with the Coumarin 343 dye and a biomimetic Fe-Fe catalyst on $\mathrm{NiO} .{ }^{23,}{ }^{86}$ It should be noted that excited and reduced PB6 give similar ground state bleaches, and both species absorb at $650 \mathrm{~nm}$. This is reflected by the fact that the decay of the $650 \mathrm{~nm}$ absorption and the $530 \mathrm{~nm}$ bleach nearly mirror each other (Figure S17). Moreover, electron transfer to the catalyst is expected to show a broad distribution of kinetics, and is the case for hole injection and charge recombination. 


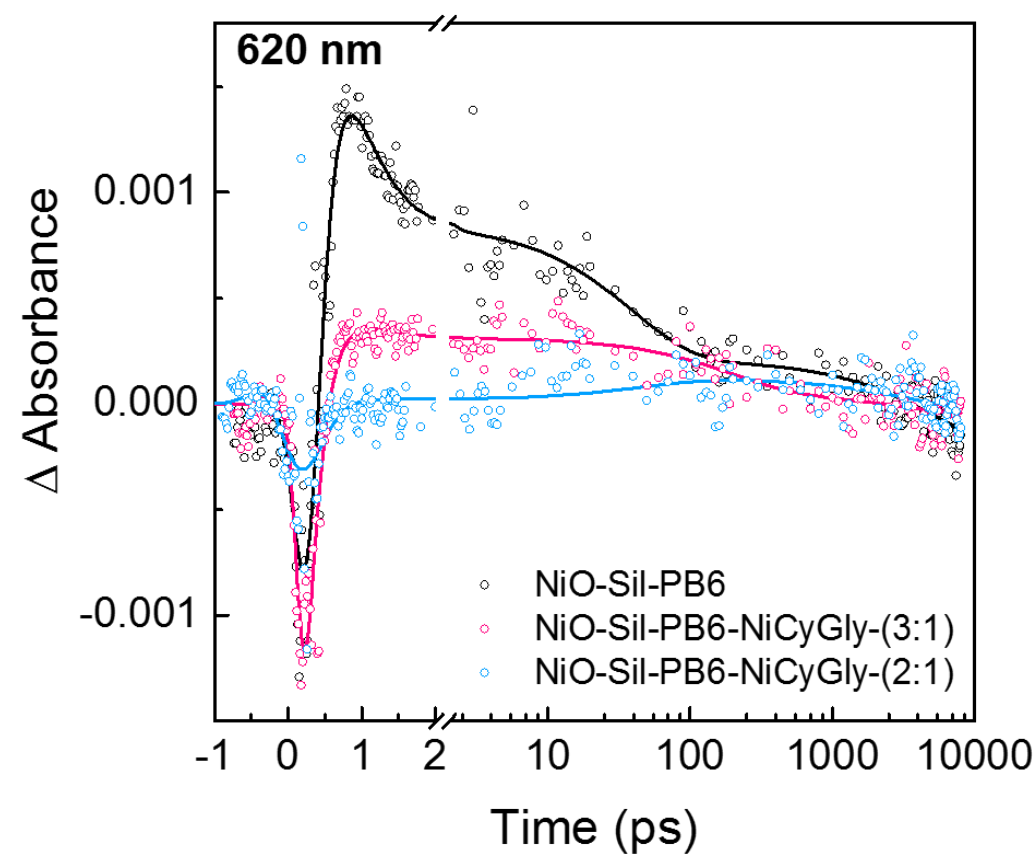

Figure 7. fsTAS traces at $620 \mathrm{~nm}$ for NiO-Sil-PB6 (black), NiO-Sil-PB6NiCyGly-(3:1) (pink) and NiO-Sil-PB6-NiCyGly-(2:1) (blue).

To summarize, we see ultrafast injection and indications of electron transfer to the catalyst on the sub-ns timescale. The small signals of $\mathrm{PB6}^{-}$compared to PB6 $^{*}$ and the competing kinetics of charge recombination and electron transfer likely contribute to the observed less than $100 \%$ quantum yield for electron transfer to the catalyst. This is consistent with the low photocurrents ( $\mu \mathrm{As})$ we observed in the photoelectrochemical investigation with catalyst present, which are considered less than ideal compared to the photocurrents observed from photoanodes (approaching $\mathrm{mA}){ }^{3}$ Furthermore, the electrodes were also screened for photocatalytic proton reduction, but did not produce any detectable $\mathrm{H}_{2}$ (SI for details). For catalysis to occur, an additional two protons and one electron must be added, resulting in more opportunities for charge recombination, further explaining the low photocurrents and lack of $\mathrm{H}_{2}$.

\section{Conclusions}

Here we reported a surface amide coupling method for photocathode assembly. This method is advantageous since it avoids tedious organic syntheses and also provides a facile screening method for different photocathode architectures. By varying the carboxylic acid and amine-derivatized molecules used to assemble 
the electrodes via amide couplings, a wide variety of photocathode architectures can be assembled and tested. In addition, to the best of our knowledge, we have reported the first NiO-based electrodes that contain silatrane-anchored molecules, which additionally showed good photoelectrochemical stability. Finally, we showed the applicability of the surface amide coupling method by incorporating a nickel catalyst on the photocathodes, which showed evidence for catalyst reduction by photoelectrochemical and fsTAS measurements. Clearly, there is room for improvement with these electrodes, and we are currently working towards this goal by using the surface-amide coupling method to assemble photocathodes with higher photocurrents and efficiencies.

\section{Associated Content}

Supporting Information: Further experimental details on the assembly and characterization of the photocathodes can be found in the SI. Dye and catalyst loadings, additional UV-Vis spectra, ATR-FTIR spectra, photoelectrochemical data, fs-TAS data, and ICP-EOS data can be found in the SI.

\section{Author Information}

Corresponding author: leif.hammarstrom@kemi.uu.se

Notes: We declare no competing financial interest.

\section{Acknowledgements}

We thank the Swedish Energy Agency (Grant no. 11674-8) for funding this research. We would also like to thank Dr. Bo Xu for helping prepare the NiO paste for these experiments. We also thank Ashleigh Castner for her help with the ICP-OES experiments. We thank Lei Tian for his advice throughout the project. We thank Dr. Jens Föhlinger and Jonas Petterson for writing the MATLAB script for the global fitting. We also thank Dr. Palas Baran Pati for synthesizing the PB6 dye. Finally, we thank Dr. Brian McCarthy for useful discussions and help editing the paper. WJS, APW, and JAL were supported by the U.S. Department of Energy (USDOE), Office of Science, Office of Basic Energy Sciences (BES), Chemical Sciences, Geosciences, and Biosciences program.

\section{References}


1. Ellabban, O.; Abu-Rub, H.; Blaabjerg, F., Renewable energy resources: Current status, future prospects and their enabling technology. Renewable Sustainable Energy Rev. 2014, 39, 748-764.

2. Administration, U. S. E. I. Annual Energy Outlook; DC, 2017.

3. Brennaman, M. K.; Dillon, R. J.; Alibabaei, L.; Gish, M. K.; Dares, C. J.; Ashford, D. L.; House, R. L.; Meyer, G. J.; Papanikolas, J. M.; Meyer, T. J., Finding the Way to Solar Fuels with Dye-Sensitized Photoelectrosynthesis Cells. J. Am. Chem. Soc. 2016, 13085-13102.

4. Young, K. J.; Martini, L. A.; Milot, R. L.; Snoeberger, R. C., III; Batista, V. S.; Schmuttenmaer, C. A.; Crabtree, R. H.; Brudvig, G. W., Light-driven water oxidation for solar fuels. Coord Chem Rev 2012, 256 (21-22), 2503-2520.

5. Wang, Y.; Suzuki, H.; Xie, J.; Tomita, O.; Martin, D. J.; Higashi, M.; Kong, D.; Abe, R.; Tang, J., Mimicking Natural Photosynthesis: Solar to Renewable H2 Fuel Synthesis by Z-Scheme Water Splitting Systems. Chem Rev 2018, 118 (10), $5201-5241$

6. McEvoy, J. P.; Brudvig, G. W., Water-splitting chemistry of photosystem II. Chem Rev 2006, 106 (11), 4455-83.

7. Li, F.; Fan, K.; Xu, B.; Gabrielsson, E.; Daniel, Q.; Li, L.; Sun, L., Organic Dye-Sensitized Tandem Photoelectrochemical Cell for Light Driven Total Water Splitting. J Am Chem Soc 2015, 137 (28), 9153-9.

8. Ashford, D. L.; Gish, M. K.; Vannucci, A. K.; Brennaman, M. K.; Templeton, J. L.; Papanikolas, J. M.; Meyer, T. J., Molecular Chromophore-Catalyst Assemblies for Solar Fuel Applications. Chem Rev 2015, 115 (23), 13006-49.

9. Yu, Z.; Li, F.; Sun, L., Recent advances in dye-sensitized photoelectrochemical cells for solar hydrogen production based on molecular components. Energy \& Environmental Science 2015, 8 (3), 760-775.

10. Tian, H., Molecular Catalyst Immobilized Photocathodes for Water/Proton and Carbon Dioxide Reduction. ChemSusChem 2015, 8 (22), 3746-59.

11. Schlapbach, L.; Zuttel, A., Hydrogen-storage materials for mobile applications. Nature 2001, 414 (6861), 353-8.

12. Gibson, E. A., Dye-sensitized photocathodes for H2 evolution. Chem Soc Rev 2017, 46 (20), 6194-6209.

13. Nikolaou, V.; Charisiadis, A.; Charalambidis, G.; Coutsolelos, A. G.; Odobel, F., Recent advances and insights in dyesensitized NiO photocathodes for photovoltaic devices. J. Mater. Chem. A 2017, 5 (40), 21077-21113.

14. Wu, H.-L.; Li, X.-B.; Tung, C.-H.; Wu, L.-Z., Recent Advances in Sensitized Photocathodes: From Molecular Dyes to Semiconducting Quantum Dots. Advanced Science 2018, 1700684.

15. Queyriaux, N.; Kaeffer, N.; Morozan, A.; Chavarot-Kerlidou, M.; Artero, V., Molecular cathode and photocathode materials for hydrogen evolution in photoelectrochemical devices. Journal of Photochemistry and Photobiology C: Photochemistry Reviews 2015, 25, 90-105.

16. Ashford, D. L.; Gish, M. K.; Vannucci, A. K.; Brennaman, M. K.; Templeton, J. L.; Papanikolas, J. M.; Meyer, T. J., Molecular Chromophore-Catalyst Assemblies for Solar Fuel Applications. Chem. Rev. 2015, 115 (23), 13006-49.

17. Fan, K.; Li, F.; Wang, L.; Daniel, Q.; Gabrielsson, E.; Sun, L., Pt-free tandem molecular photoelectrochemical cells for water splitting driven by visible light. Phys Chem Chem Phys 2014, 16 (46), 25234-40. 
18. Wood, C. J.; Summers, G. H.; Clark, C. A.; Kaeffer, N.; Braeutigam, M.; Carbone, L. R.; D'Amario, L.; Fan, K.; Farre, Y.; Narbey, S.; Oswald, F.; Stevens, L. A.; Parmenter, C. D.; Fay, M. W.; La Torre, A.; Snape, C. E.; Dietzek, B.; Dini, D.; Hammarstrom, L.; Pellegrin, Y.; Odobel, F.; Sun, L.; Artero, V.; Gibson, E. A., A comprehensive comparison of dye-sensitized $\mathrm{NiO}$ photocathodes for solar energy conversion. Phys Chem Chem Phys 2016, 18 (16), 10727-38.

19. Tong, L.; Iwase, A.; Nattestad, A.; Bach, U.; Weidelener, M.; Götz, G.; Mishra, A.; Bäuerle, P.; Amal, R.; Wallace, G. G.; Mozer, A. J., Sustained solar hydrogen generation using a dye-sensitised NiO photocathode/BiVO4 tandem photoelectrochemical device. Energy \& Environmental Science 2012, 5 (11), 9472.

20. Morandeira, A.; Boschloo, G.; Hagfeldt, A.; Hammarstrom, L., Photoinduced ultrafast dynamics of coumarin 343 sensitized p-type-nanostructured NiO films. J Phys Chem B 2005, 109 (41), 19403-10.

21. Qin, P.; Wiberg, J.; Gibson, E. A.; Linder, M.; Li, L.; Brinck, T.; Hagfeldt, A.; Albinsson, B.; Sun, L., Synthesis and Mechanistic Studies of Organic Chromophores with Different Energy Levels for p-Type Dye-Sensitized Solar Cells. The Journal of Physical Chemistry C 2010, 114 (10), 4738-4748.

22. Odobel, F.; Pellegrin, Y.; Gibson, E. A.; Hagfeldt, A.; Smeigh, A. L.; Hammarström, L., Recent advances and future directions to optimize the performances of p-type dye-sensitized solar cells. Coordination Chemistry Reviews 2012, 256 (21-22), 2414-2423.

23. Antila, L. J.; Ghamgosar, P.; Maji, S.; Tian, H.; Ott, S.; Hammarström, L., Dynamics and Photochemical H2 Evolution of Dye-NiO Photocathodes with a Biomimetic FeFe-Catalyst. ACS Energy Letters 2016, 1 (6), 1106-1111.

24. Daeneke, T.; Yu, Z.; Lee, G. P.; Fu, D.; Duffy, N. W.; Makuta, S.; Tachibana, Y.; Spiccia, L.; Mishra, A.; Bäuerle, P.; Bach, U., Dominating Energy Losses in NiO p-Type Dye-Sensitized Solar Cells. Advanced Energy Materials 2015, 5 (4).

25. D'Amario, L.; Antila, L. J.; Pettersson Rimgard, B.; Boschloo, G.; Hammarstrom, L., Kinetic Evidence of Two Pathways for Charge Recombination in NiO-Based Dye-Sensitized Solar Cells. J Phys Chem Lett 2015, 6 (5), 779-83.

26. D'Amario, L.; Föhlinger, J.; Boschloo, G.; Hammarström, L., Unveiling hole trapping and surface dynamics of NiO nanoparticles. Chemical Science 2018, 9 (1), 223-230.

27. D'Amario, L.; Jiang, R.; Cappel, U. B.; Gibson, E. A.; Boschloo, G.; Rensmo, H.; Sun, L.; Hammarstrom, L.; Tian, H., Chemical and Physical Reduction of High Valence Ni States in Mesoporous NiO Film for Solar Cell Application. ACS App/ Mater Interfaces 2017, 9 (39), 33470-33477.

28. Morandeira, A.; Boschloo, G.; Hagfeldt, A.; Hammarström, L., Coumarin 343-NiO Films as Nanostructured Photocathodes in Dye-Sensitized Solar Cells: Ultrafast Electron Transfer, Effect of the I3-/I- Redox Couple and Mechanism of Photocurrent Generation. The Journal of Physical Chemistry C 2008, 112 (25), 9530-9537.

29. Mori, S.; Fukuda, S.; Sumikura, S.; Takeda, Y.; Tamaki, Y.; Suzuki, E.; Abe, T., Charge-Transfer Processes in DyeSensitized NiO Solar Cells. The Journal of Physical Chemistry C 2008, 112 (41), 16134-16139.

30. Black, F. A.; Wood, C. J.; Ngwerume, S.; Summers, G. H.; Clark, I. P.; Towrie, M.; Camp, J. E.; Gibson, E. A., Chargetransfer dynamics at the dye-semiconductor interface of photocathodes for solar energy applications. Faraday Discuss 2017, 198, 449-461. 
31. Brautigam, M.; Kubel, J.; Schulz, M.; Vos, J. G.; Dietzek, B., Hole injection dynamics from two structurally related Rubipyridine complexes into $\mathrm{NiO}(\mathrm{x})$ is determined by the substitution pattern of the ligands. Phys Chem Chem Phys 2015, 17 (12), 7823-30.

32. Hao, Y.; Wood, C. J.; Clark, C. A.; Calladine, J. A.; Horvath, R.; Hanson-Heine, M. W.; Sun, X. Z.; Clark, I. P.; Towrie,

M.; George, M. W.; Yang, X.; Sun, L.; Gibson, E. A., Can aliphatic anchoring groups be utilised with dyes for p-type dye sensitized solar cells? Dalton Trans 2016, 45 (18), 7708-19.

33. Huang, Z.; Natu, G.; Ji, Z.; He, M.; Yu, M.; Wu, Y., Probing the Low Fill Factor of NiO p-Type Dye-Sensitized Solar Cells. The Journal of Physical Chemistry C 2012, 116 (50), 26239-26246.

34. Ji, Z.; Natu, G.; Huang, Z.; Kokhan, O.; Zhang, X.; Wu, Y., Synthesis, Photophysics, and Photovoltaic Studies of Ruthenium Cyclometalated Complexes as Sensitizers for p-Type NiO Dye-Sensitized Solar Cells. The Journal of Physical Chemistry C 2012, 116 (32), 16854-16863.

35. Ji, Z.; Wu, Y., Photoinduced Electron Transfer Dynamics of Cyclometalated Ruthenium (II)-Naphthalenediimide Dyad at NiO Photocathode. The Journal of Physical Chemistry C 2013, 117 (36), 18315-18324.

36. Shan, B.; Nayak, A.; Brennaman, M. K.; Liu, M.; Marquard, S. L.; Eberhart, M. S.; Meyer, T. J., Controlling Vertical and Lateral Electron Migration Using a Bifunctional Chromophore Assembly in Dye-Sensitized Photoelectrosynthesis Cells. J Am Chem Soc 2018.

37. Shan, B.; Sherman, B. D.; Klug, C. M.; Nayak, A.; Marquard, S. L.; Liu, Q.; Bullock, R. M.; Meyer, T. J., Modulating Hole Transport in Multilayered Photocathodes with Derivatized p-Type Nickel Oxide and Molecular Assemblies for Solar-Driven Water Splitting. J Phys Chem Lett 2017, 8 (18), 4374-4379.

38. Dillon, R. J.; Alibabaei, L.; Meyer, T. J.; Papanikolas, J. M., Enabling Efficient Creation of Long-Lived Charge-Separation on Dye-Sensitized NiO Photocathodes. ACS Appl Mater Interfaces 2017, 9 (32), 26786-26796.

39. Gross, M. A.; Creissen, C. E.; Orchard, K. L.; Reisner, E., Photoelectrochemical hydrogen production in water using a layer-by-layer assembly of a Ru dye and Ni catalyst on NiO. Chemical Science 2016, 7 (8), 5537-5546.

40. Shan, B.; Das, A. K.; Marquard, S.; Farnum, B. H.; Wang, D.; Bullock, R. M.; Meyer, T. J., Photogeneration of hydrogen from water by a robust dye-sensitized photocathode. Energy \& Environmental Science 2016, 9 (12), 3693-3697.

41. Shan, B.; Farnum, B. H.; Wee, K.-R.; Meyer, T. J., Generation of Long-Lived Redox Equivalents in Self-Assembled Bilayer Structures on Metal Oxide Electrodes. The Journal of Physical Chemistry C 2017, 121 (11), 5882-5890.

42. Leem, G.; Black, H. T.; Shan, B.; Bantang, J. P. O.; Meyer, T. J.; Reynolds, J. R.; Schanze, K. S., Photocathode Chromophore-Catalyst Assembly via Layer-By-Layer Deposition of a Low Band-Gap Isoindigo Conjugated Polyelectrolyte. ACS Applied Energy Materials 2018, 1 (1), 62-67.

43. Click, K. A.; Beauchamp, D. R.; Huang, Z.; Chen, W.; Wu, Y., Membrane-Inspired Acidically Stable Dye-Sensitized Photocathode for Solar Fuel Production. J Am Chem Soc 2016, 138 (4), 1174-9. 
44. van den Bosch, B.; Rombouts, J. A.; Orru, R. V. A.; Reek, J. N. H.; Detz, R. J., Nickel-Based Dye-Sensitized

Photocathode: Towards Proton Reduction Using a Molecular Nickel Catalyst and an Organic Dye. ChemCatChem 2016, 8 (7), 1392-1398.

45. Kaeffer, N.; Windle, C. D.; Brisse, R.; Gablin, C.; Leonard, D.; Jousselme, B.; Chavarot-Kerlidou, M.; Artero, V., Insights into the mechanism and aging of a noble-metal free H2-evolving dye-sensitized photocathode. Chem Sci 2018, 9 (32), 6721 6738.

46. Windle, C. D.; Kumagai, H.; Higashi, M.; Brisse, R.; Bold, S.; Jousselme, B.; Chavarot-Kerlidou, M.; Maeda, K.; Abe, R.; Ishitani, O.; Artero, V., Earth-Abundant Molecular Z-Scheme Photoelectrochemical Cell for Overall Water-Splitting. J Am Chem Soc 2019, 141 (24), 9593-9602.

47. Pati, P. B.; Zhang, L.; Philippe, B.; Fernandez-Teran, R.; Ahmadi, S.; Tian, L.; Rensmo, H.; Hammarstrom, L.; Tian, H., Insights into the Mechanism of a Covalently Linked Organic Dye-Cobaloxime Catalyst System for Dye-Sensitized Solar Fuel Devices. ChemSusChem 2017, 10 (11), 2480-2495.

48. Ji, Z.; He, M.; Huang, Z.; Ozkan, U.; Wu, Y., Photostable p-type dye-sensitized photoelectrochemical cells for water reduction. J Am Chem Soc 2013, 135 (32), 11696-9.

49. Kaeffer, N.; Massin, J.; Lebrun, C.; Renault, O.; Chavarot-Kerlidou, M.; Artero, V., Covalent Design for Dye-Sensitized H2-Evolving Photocathodes Based on a Cobalt Diimine-Dioxime Catalyst. J Am Chem Soc 2016, 138 (38), 12308-12311. 50. Lyu, S.; Massin, J.; Pavone, M.; Muñoz-García, A. B.; Labrugère, C.; Toupance, T.; Chavarot-Kerlidou, M.; Artero, V.; Olivier, C., H2-Evolving Dye-Sensitized Photocathode Based on a Ruthenium-Diacetylide/Cobaloxime Supramolecular Assembly. ACS Applied Energy Materials 2019, 2 (7), 4971-4980.

51. Poldme, N.; O'Reilly, L.; Fletcher, I.; Portoles, J.; Sazanovich, I. V.; Towrie, M.; Long, C.; Vos, J. G.; Pryce, M. T.; Gibson, E. A., Photoelectrocatalytic H2 evolution from integrated photocatalysts adsorbed on NiO. Chem Sci 2019, 10 (1), $99-$ 112.

52. Xu, B.; Tian, L.; Etman, A. S.; Sun, J.; Tian, H., Solution-processed nanoporous NiO-dye-ZnO photocathodes: Toward efficient and stable solid-state p-type dye-sensitized solar cells and dye-sensitized photoelectrosynthesis cells. Nano Energy 2019, 55, 59-64.

53. Shan, B.; Nayak, A.; N. Sampaio, R.; Eberhart, M. S.; Troian-Gautier, L.; Brennaman, M. K.; Meyer, G. J.; Meyer, T. J., Direct photoactivation of a nickel-based, water-reduction photocathode by a highly conjugated supramolecular chromophore. Energy \& Environmental Science 2018, 11 (2), 447-455.

54. Creissen, C. E.; Warnan, J.; Reisner, E., Solar H2 generation in water with a CuCrO2 photocathode modified with an organic dye and molecular Ni catalyst. Chemical Science 2018, 9 (6), 1439-1447.

55. Kamire, R. J.; Majewski, M. B.; Hoffeditz, W. L.; Phelan, B. T.; Farha, O. K.; Hupp, J. T.; Wasielewski, M. R., Photodriven hydrogen evolution by molecular catalysts using Al2O3-protected perylene-3,4-dicarboximide on $\mathrm{NiO}$ electrodes. Chem Sci 2017, $8(1), 541-549$. 
56. Materna, K. L.; Crabtree, R. H.; Brudvig, G. W., Anchoring groups for photocatalytic water oxidation on metal oxide surfaces. Chem Soc Rev 2017, 46 (20), 6099-6110.

57. Materna, K. L.; Jiang, J.; Regan, K. P.; Schmuttenmaer, C. A.; Crabtree, R. H.; Brudvig, G. W., Optimization of Photoanodes for Photocatalytic Water Oxidation by Combining a Heterogenized Iridium Water-Oxidation Catalyst with a HighPotential Porphyrin Photosensitizer. ChemSusChem 2017, 10 (22), 4526-4534.

58. Kamire, R. J.; Materna, K. L.; Hoffeditz, W. L.; Phelan, B. T.; Thomsen, J. M.; Farha, O. K.; Hupp, J. T.; Brudvig, G. W.; Wasielewski, M. R., Photodriven Oxidation of Surface-Bound Iridium-Based Molecular Water-Oxidation Catalysts on Perylene3,4-dicarboximide-Sensitized TiO2 Electrodes Protected by an Al2O3 Layer. The Journal of Physical Chemistry C 2017, 121 (7), $3752-3764$

59. McNamara, W. R.; Milot, R. L.; Song, H.-e.; Snoeberger lii, R. C.; Batista, V. S.; Schmuttenmaer, C. A.; Brudvig, G. W.; Crabtree, R. H., Water-stable, hydroxamate anchors for functionalization of $\mathrm{TiO} 2$ surfaces with ultrafast interfacial electron transfer. Energy Environ. Sci. 2010, 3 (7), 917-923.

60. McNamara, W. R.; Snoeberger III, R. C.; Li, G.; Richter, C.; Allen, L. J.; Milot, R. L.; Schmuttenmaer, C. A.; Crabtree, R. H.; Brudvig, G. W.; Batista, V. S., Hydroxamate anchors for water-stable attachment to TiO2 nanoparticles. Energy Environ. Sci. 2009, 2 (11), 1173-1175.

61. Jiang, J.; Spies, J. A.; Swierk, J. R.; Matula, A. J.; Regan, K. P.; Romano, N.; Brennan, B. J.; Crabtree, R. H.; Batista, V. S.; Schmuttenmaer, C. A.; Brudvig, G. W., Direct Interfacial Electron Transfer from High-Potential Porphyrins into Semiconductor Surfaces: A Comparison of Linkers and Anchoring Groups. The Journal of Physical Chemistry C 2018, 122 (25), 13529-13539.

62. Jiang, J.; Spies, J. A.; Swierk, J. R.; Matula, A. J.; Regan, K. P.; Romano, N.; Brennan, B. J.; Crabtree, R. H.; Batista, V. S.; Schmuttenmaer, C. A.; Brudvig, G. W., Direct Interfacial Electron Transfer from High-Potential Porphyrins into Semiconductor Surfaces: A Comparison of Linkers and Anchoring Groups. The Journal of Physical Chemistry C 2018, accepted.

63. Materna, K. L.; Brennan, B. J.; Brudvig, G. W., Silatranes for binding inorganic complexes to metal oxide surfaces. Dalton Trans. 2015, 44 (47), 20312-5.

64. Materna, K. L.; Jiang, J.; Crabtree, R. H.; Brudvig, G. W., Silatrane Anchors for Metal Oxide Surfaces: Optimization for Potential Photocatalytic and Electrocatalytic Applications. ACS Appl Mater Interfaces 2018.

65. Brennan, B. J.; Gust, D.; Brudvig, G. W., Organosilatrane building blocks. Tetrahedron Lett. 2014, 55 (5), $1062-1064$.

66. Brennan, B. J.; Keirstead, A. E.; Liddell, P. A.; Vail, S. A.; Moore, T. A.; Moore, A. L.; Gust, D., 1-(3'Amino)propylsilatrane derivatives as covalent surface linkers to nanoparticulate metal oxide films for use in photoelectrochemical cells. Nanotechnology 2009, 20 (50), 505203.

67. Frye, C. L.; Vincent, G. A.; Finzel, W. A., Pentacoordinate silicon compounds. V. Novel silatrane chemistry. J. Am. Chem. Soc. 1971,93 (25), 6805-6811. 
68. Materna, K. L.; Rudshteyn, B.; Brennan, B. J.; Kane, M. H.; Bloomfield, A. J.; Huang, D. L.; Shopov, D. Y.; Batista, V. S.; Crabtree, R. H.; Brudvig, G. W., Heterogenized Iridium Water-Oxidation Catalyst from a Silatrane Precursor. ACS Catal. 2016, 6 (8), 5371-5377.

69. Lee, K.-R.; Bettis Homan, S.; Kodaimati, M.; Schatz, G. C.; Weiss, E. A., Near-Quantitative Yield for Transfer of NearInfrared Excitons within Solution-Phase Assemblies of PbS Quantum Dots. The Journal of Physical Chemistry C 2016, 120 (39), 22186-22194.

70. Booth, M. A.; Kannappan, K.; Hosseini, A.; Partridge, A., In-Depth Electrochemical Investigation of Surface Attachment Chemistry via Carbodiimide Coupling. Langmuir 2015, 31 (29), 8033-8041.

71. You, J.-M.; Han, H. S.; Lee, H. K.; Cho, S.; Jeon, S., Enhanced electrocatalytic activity of oxygen reduction by cobaltporphyrin functionalized with graphene oxide in an alkaline solution. International Journal of Hydrogen Energy 2014, 39 (10), 4803-4811.

72. Wayu, M. B.; Pannell, M. J.; Labban, N.; Case, W. S.; Pollock, J. A.; Leopold, M. C., Functionalized carbon nanotube adsorption interfaces for electron transfer studies of galactose oxidase. Bioelectrochemistry 2019, 125, 116-126.

73. Ellebracht, N. C.; Jones, C. W., Amine functionalization of cellulose nanocrystals for acid-base organocatalysis: surface chemistry, cross-linking, and solvent effects. Cellulose 2018, 25 (11), 6495-6512.

74. Tian, L.; Fohlinger, J.; Pati, P. B.; Zhang, Z.; Lin, J.; Yang, W.; Johansson, M.; Kubart, T.; Sun, J.; Boschloo, G.; Hammarstrom, L.; Tian, H., Ultrafast dye regeneration in a core-shell NiO-dye-TiO2 mesoporous film. Phys Chem Chem Phys 2017, 20 (1), 36-40.

75. Tian, L.; Fohlinger, J.; Zhang, Z.; Pati, P. B.; Lin, J.; Kubart, T.; Hua, Y.; Sun, J.; Kloo, L.; Boschloo, G.; Hammarstrom, L.; Tian, H., Solid state p-type dye sensitized NiO-dye-TiO2 core-shell solar cells. Chem Commun (Camb) 2018, 54 (30), 3739-3742.

76. Gibson, E. A.; Le Pleux, L.; Fortage, J.; Pellegrin, Y.; Blart, E.; Odobel, F.; Hagfeldt, A.; Boschloo, G., Role of the triiodide/iodide redox couple in dye regeneration in p-type dye-sensitized solar cells. Langmuir 2012, 28 (15), 6485-93.

77. Brennan, B. J.; Llansola Portoles, M. J.; Liddell, P. A.; Moore, T. A.; Moore, A. L.; Gust, D., Comparison of silatrane, phosphonic acid, and carboxylic acid functional groups for attachment of porphyrin sensitizers to TiO2 in photoelectrochemical cells. Phys. Chem. Chem. Phys. 2013, 15 (39), 16605-14.

78. Honda, F.; Hirokawa, K., The infrared spectroscopic study of metals intruded into a silica framework. Spectrochimica Acta 1972, 28A, 1793-1803.

79. Hoogeveen, D. A.; Fournier, M.; Bonke, S. A.; Nattestad, A.; Mishra, A.; Bäuerle, P.; Spiccia, L.; Mozer, A. J.; Simonov, A. N., Origin of Photoelectrochemical Generation of Dihydrogen by a Dye-Sensitized Photocathode without an Intentionally Introduced Catalyst. The Journal of Physical Chemistry C 2017, 121 (46), 25836-25846.

80. Zhang, L.; Boschloo, G.; Hammarstrom, L.; Tian, H., Solid state p-type dye-sensitized solar cells: concept, experiment and mechanism. Phys Chem Chem Phys 2016, 18 (7), 5080-5. 
81. Dutta, A.; DuBois, D. L.; Roberts, J. A.; Shaw, W. J., Amino acid modified Ni catalyst exhibits reversible H2 oxidation/production over a broad pH range at elevated temperatures. Proc Natl Acad Sci U S A 2014, 111 (46), 16286-91.

82. Dutta, A.; Lense, S.; Hou, J.; Engelhard, M. H.; Roberts, J. A.; Shaw, W. J., Minimal proton channel enables H2 oxidation and production with a water-soluble nickel-based catalyst. J Am Chem Soc 2013, 135 (49), 18490-6.

83. Ginovska-Pangovska, B.; Dutta, A.; Reback, M. L.; Linehan, J. C.; Shaw, W. J., Beyond the active site: the impact of the outer coordination sphere on electrocatalysts for hydrogen production and oxidation. Acc. Chem. Res. 2014, 47 (8), 2621-30. 84. Oughli, A. A.; Ruff, A.; Boralugodage, N. P.; Rodriguez-Macia, P.; Plumere, N.; Lubitz, W.; Shaw, W. J.; Schuhmann, W.; Rudiger, O., Dual properties of a hydrogen oxidation Ni-catalyst entrapped within a polymer promote self-defense against oxygen. Nat Commun 2018, 9 (1), 864.

85. Priyadarshani, N.; Dutta, A.; Ginovska, B.; Buchko, G. W.; O’Hagan, M.; Raugei, S.; Shaw, W. J., Achieving Reversible $\mathrm{H} 2 / \mathrm{H}+$ Interconversion at Room Temperature with Enzyme-Inspired Molecular Complexes: A Mechanistic Study. ACS Catal. 2016, 6 (9), 6037-6049.

86. Brown, A. M.; Antila, L. J.; Mirmohades, M.; Pullen, S.; Ott, S.; Hammarstrom, L., Ultrafast Electron Transfer Between Dye and Catalyst on a Mesoporous NiO Surface. J Am Chem Soc 2016, 138 (26), 8060-3. 